UDK 620.193/.199

DOI: https://doi.org/10.24867/10AM08Ponjevic

\title{
METALNI BIOMATERIJALI - KOROZIJA, ISPITIVANJE, PREVENCIJA I MONITORING
}

\section{METALLIC BIOMATERIALS - CORROSION, TESTING, PREVENTION AND MONITORING}

\author{
Nikola Ponjević, Dragan Rajnović, Fakultet tehničkih nauka, Novi Sad
}

\begin{abstract}
Oblast - PROIZVODNO MAŠINSTVO
Kratak sadržaj - U ovom radu su detaljno opisane osobine i mikrostruktura metalnih biomaterijala sa akcentom na koroziji ovih materijala, njihovim ispitivanjem, prevencijom $i$ monitoringom. Ispitivane su tri legure: nerđajući čelik 316LVM, titanijumova legura Ti-6Al-4V i kobaltova legura Co-Cr-Mo. U eksperimentalnom delu uzorci su potopljeni u rastvor soli i kiseline, te su nakon toga posmatrani na SEM $i$ svetlosnom mikroskopu. Utvrđeno je da su sva tri materijala otporna u većoj meri na koroziju u rastvoru kiselina ili slanom rastvoru.
\end{abstract}

Ključne reči: Korozija, Biomaterijali, Ispitivanje

Abstract - This paper describes in details the properties and the microstructure of metallic biomaterials with emphasis on the corrosion of these materials, their testing, prevention and monitoring. Three alloys were tested: 316LVM stainless steel, Ti-6Al-4V titanium alloy and Co-Cr-Mo cobalt alloy. In the experimental part, the samples were immersed in a solution of salt and acid and then observed under the SEM and under the light microscope. It was found that all 3 materials are generally resistant to corrosion in solution of acids or salts.

Key words: Corrosion, Biomaterials, Testing

\section{UVOD}

\subsection{Metalni biomaterijali}

Osnovni zahtev za biomaterijale je da moraju da poseduju odgovarajuće karakteristike, čak i pri radu u veoma zahtevnom okruženju, kakvo je ljudsko telo, odnosno da poseduju odgovarajuću biokompatibilnost. Biokompatibilnost je opisni izraz kojim se označava sposobnost materijala da se ponaša na odgovarajući način u sredini (živom tkivu) u kojem se koristi [1].

Metali poseduju odgovarajuće osobine, kao što su velika tvrdoća, duktilnost, otpornost na lom, čvrstoća, otpornost na koroziju, mogućnost oblikovanja i biokompatibilnost, neophodne za podnošenje opterećenja prilikom fiksiranja fraktura parcijalne i totalne artroplastike zglobova. Tri legure metala koje se najviše koriste u medicini su [2,3]:

- legure nerđajućeg čelika.

- legure na bazi titanijuma, i

- legure na bazi kobalta.

\section{NAPOMENA:}

Ovaj rad proistekao je iz master rada čiji mentor je bio dr Dragan Rajnović, docent.

\section{KOROZIJA}

Korozija se definiše kao degradacija materijala u sastavne atome pod uticajem hemijske reakcije koja se dešava između materijala i njihove okoline [5].

\subsection{Korozija biokompatibilnih metala}

Bioimplantati bi trebalo da poseduju veoma visoku otpornost na koroziju i habanje zbog izloženosti visoko korozionom okruženju unutar tela i različitim intenzitetima opterećenja. Pored ovoga, bioimplantati treba da budu otporni i na zamor i lom [6].

\subsection{Vrste korozija u metalnim implantatima}

Korozija metala se dešava kao rezultat interakcije između elektrohemijskih ćelija što vodi raznim vrstama korozionih reakcija [5]. Neke od najčešćih vrsta korozije navode se dalje u tekstu.

1) Ravnomerna ili uniformna korozija se dešava kada je čitava površina metala izložena katodičnim reagentima tokom lokalizovane korozije.

2) Piting korozija označava određenu vrstu lokalizovane korozije. Piting se javlja u obliku tačaka ili udubljenja na površini.

3) Tribokorozija je mehanizam trošenja pri kojem preovladavaju hemijske ili elektrohemijske reakcije materijala s okolinom.

4) Korozioni zamor je rezultat kombinovanog delovanja promenljivih napona i korozionog okruženja.

5) Naponska korozija se odnosi na razgradnju i/ili stvaranje produkata korozije određene površine metala ili legura u elektrolitu, zbog toga što je metal konstantno podvrgnut različitim naprezanjima.

6) Galvanska korozija se javlja u spoju dva metala od kojih metal sa pozitivnijim potencijalom predstavlja katodno, a metal sa negativnijim potencijalom predstavlja anodno mesto.

7) Korozija u zazoru se odigrava usled brzog utroška oksidacionog sredstva u maloj zapremini zazora.
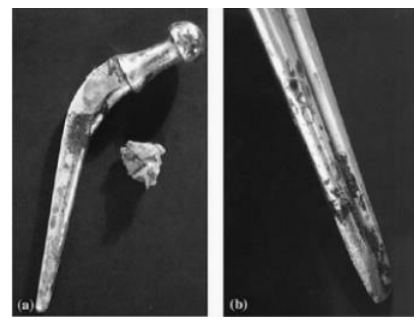

Slika 1. (a) Površinska korozija i (b) piting korozija nakon uklanjanja implantata [5] 


\subsection{Efekti korozije na implantat}

Kako materijal kreće da korodira, rastvaranje metala dovodi do erozije koja zatim dovodi do loma implantata [6]. Kada dođe do loma materijala, korozioni proces se ubrzava usled povećanog površinskog sloja i gubitka zaštitne oksidne prevlake. Ukoliko se metalni fragmenti ne uklone hirurški, moguće je daljnje rastvaranje i fragmentacija koji mogu dovesti do zapaljenja okolnog tkiva.

\subsection{Efekti korozije na ljudsko telo}

Korodirani implantati u ljudskom telu dovode do oslobađanja veoma štetnih i toksičnih jona $u$ telesne tečnosti. Joni metala koji se oslobađaju iz implantata su prepoznati kao vodeći razlog kliničkih problema i alergijskih reakcija [5]. Oslobađanje jona može izazvati neželjene posledice po zdravlje, pa čak i uzrokovati smrt pacijenta.

\subsection{Korozija konvencionalnih biolegura}

Kod nerđajućeg čelika manje prisustvo ugljenika smanjuje verovatnoću stvaranja hrom karbida što dovodi do integranularne korozije. Ipak, nerđajući čelik je podložan lokalizovanoj koroziji usled delovanja hloridnih jona i redukovanih jedinjenja sumpora. Prisustvo mikroorganizama na metalnim površinama često dovodi do usko lokalizovanih oštećenja u koncentraciji elektrolitnih sastojaka, nivoa $\mathrm{pH}$ i kiseonika.

Upotreba titanijuma i njegovih legura je postala sveprisutna usled njegove čvrstoće, niskog modula elastičnosti, manje gustine i dobre kombinacije mehaničke i izvanredne korozione otpornosti [6]. Titanijum je inertan i otporan na koroziju usled izlaganja telesnim tečnostima i tkivu što ga čini potpuno biokompatibilnim, ali je takođe utvrđeno da mogu izazvati dugotrajne medicinske probleme kao što su periferna neuropatija, osteomalacija i Alchajmerova bolest usled ispuštanja jona aluminijuma i vanadijuma iz legure.

Kobaltove legure poseduju bolju čvrstoću, modul elastičnosti, otpornost na abraziju i koroziju u poređenju sa legurama nerđajućeg čelika. Kao i kod nerđajućeg čelika, hrom je u ovim legurama odgovoran za najveći deo njihove otpornosti na koroziju. Međutim, u ovim legurama, kobalt takođe ima veliki uticaj, što ih čini izuzetno otpornim na koroziju. Biokorozija $u$ ovim legurama je jedan od glavnih problema pošto ona dovodi do ispuštanja jona metala koji izazivaju neželjena dejstva.

\subsection{Monitoring (praćenje) korozije u biomaterijalima}

Korozija u biomaterijalima se smatra elektrohemijskom reakcijom. Na bazi toga, većina tehnika za nadgledanje procesa degradacije koristi elektrohemijski pristup [7]. Elektrohemijska istraživanja su se uvek sprovodila u simuliranim telesnim tečnostima kao što su aerovana morska voda, Ringerov rastvor, Henkov rastvor i fosfatni pufer. Tehnike koje su korišćene uključuju potenciostatičku i potenciodinamičku polarizaciju, kao i spektroskopiju elektrohemijske impedanse, dok se količina jona merila koristeći uređaje za atomsku apsorpcionu spektroskopiju i atomsku emisionu spektroskopiju. Tri tehnike koje su razvijene i upotrebljavaju se za dobijanje detaljnih kvantitativnih informacija o elektrohemijskom ponašanju metalnih biomaterijala su skening elektrohemijska mikroskopija (SECM), testiranje pomoću elektrohemijskog skrečinga pri velikim brzinama i spektroskopiju impedanse sa postepenom polarizacijom.

\subsection{Prevencija korozije biomaterijala}

Preventivne mere za korozione sisteme uključuju: dizajn, selekciju materijala, površinske modifikacije (inhibitore i prevlake), modifikacije materijala (legiranje, termička obrada), kao i elektrohemijske tehnike (katodna i anodna zaštita) [7].

\section{EKSPERIMENTALNA PROCEDURA}

\subsection{Ispitivani materijali}

Ispitivanje pojave korozije je izvršeno na sledećim uzorcima polaznog materijala:

- $\quad 316 L V M$ - šipka u vučenom stanju

- Ti-6Al-4V - šipka u kovanom stanju

- Co-Cr-Mo - šipka u livenom stanju

Tabela 1. Uporedni prikaz standardnih hemijskih sastava ispitivanih materijala (mass. \%) [8, 9, 10]

\begin{tabular}{|c|c|c|c|}
\hline \multirow{2}{*}{ Hemijski elementi } & \multicolumn{3}{|c|}{ Legura } \\
\cline { 2 - 4 } & 316LVM & Ti-6Al-4V & $\begin{array}{c}\text { Liveni } \\
\text { Co-Cr-Mo }\end{array}$ \\
\hline $\mathrm{Cr}(\%)$ & 17.5 & - & $26.5-30$ \\
\hline $\mathrm{Mo}(\%)$ & 2.8 & - & $4.5-7.0$ \\
\hline $\mathrm{Ni}(\%)$ & 14 & - & max. 1.0 \\
\hline $\mathrm{Fe}(\%)$ & osnova & max. 0.25 & max. 1.0 \\
\hline $\mathrm{Al}(\%)$ & - & $5.5-6.5$ & - \\
\hline $\mathrm{V} \mathrm{( \% )}$ & - & $3.5-4.5$ & - \\
\hline $\mathrm{C}(\%)$ & $\leq 0.025$ & max. 0.08 & - \\
\hline
\end{tabular}

\subsection{Priprema metalografskih uzoraka}

Uzorci za ispitivanje mikrostrukture su isečeni iz polaznog šipkastog materijala, i potom pripremljeni standardnom metalografskom tehnikom pripreme koja se sastojala od montiranja, brušenja, poliranja i nagrizanja uzoraka.

\subsection{Izlaganje uzoraka korozionoj sredini}

Izlaganje uzoraka korozionoj sredini je izvršeno potapanjem uzoraka u 2 različita rastvora:

- Slani rastvor - Ringerov rastvor [11]

Sastav: Destilovana voda $+8.60 \mathrm{gL}^{-1} \mathrm{NaCl}+$ $0.30 \mathrm{gL}^{-1} \mathrm{KCl}+0.33 \mathrm{gL}^{-1} \mathrm{CaCl}_{2}$

- Alkoholni rastvor kiselina [12]

Sastav: Alkohol $+11.5 \% \mathrm{H}_{2} \mathrm{SO}_{4}+1.2 \% \mathrm{HCl}+$ $1 \% \mathrm{CuCl}_{2}+1 \% \mathrm{FeCl}_{3}$

Potapanje u oba rastvora je izvršeno u vremenu od 96 časova, na sobnoj temperaturi.

Uzorci su nakon potapanja u rastvore posmatrani na svetlosnom mikroskopu Leitz Orthoplan i SEM mikroskopu JEOL JSM 6460 LV sa EDS sistemom Inca, Oxford Instruments u cilju određivanja hemijskog sastava produkata korozije.

\section{REZULTATI I DISKUSIJA}

\subsection{Nerđajući čelik 316LVM}

Mikrostruktura nerđajućeg čelika 316LVM je u potpunosti austenitna sa jasno vidljivim deformacionim dvojnicima $u$ poprečnom preseku. Veličina zrna na poprečnom preseku odgovara indeksu veličine zrna $G=7$. 
Izgled produkata korozije izloženih dejstvu rastvora soli koji su ispitivani EDS analizom prikazan je na slici 2, dok je hemijski sastav produkata dat u tabeli 2. Produkti korozije su prvenstveno železni oksidi. Pored produkata korozije, prisutni su i tragovi slanog rastvora, u vidu elemenata $\mathrm{Na}, \mathrm{Ca}$, i K. Korozija se javlja na mestu smanjene koncentracije hroma (spec. 4).

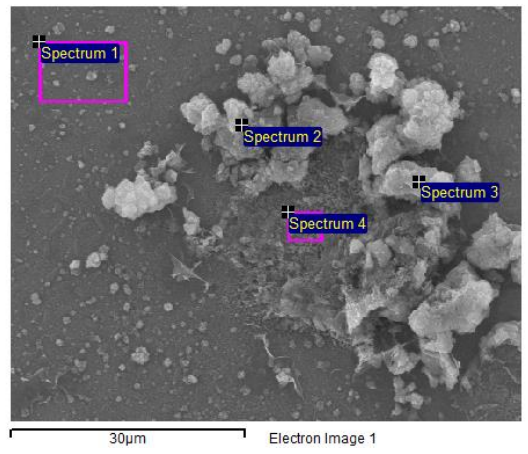

Slika 2. Mesto EDS analize na leguri nerđajućeg čelika izloženog rastvoru soli

Tabela 2. Hemijski sastav produkata sa slike 2 [mass. \%]

\begin{tabular}{|c|c|c|c|c|c|c|c|c|c|c|c|}
\hline Spec. & $\mathbf{O}$ & $\mathbf{N a}$ & $\mathbf{S i}$ & $\mathbf{S}$ & $\mathbf{K}$ & $\mathbf{C a}$ & $\mathbf{C r}$ & $\mathbf{M n}$ & $\mathbf{F e}$ & $\mathbf{N i}$ & $\mathbf{M o}$ \\
\hline $\mathbf{1}$ & 3.6 & 0.1 & 0.4 & 0.1 & 0.05 & 0.07 & 15.5 & 1.7 & 62.1 & 13.3 & 2.6 \\
\hline $\mathbf{2}$ & 26.2 & 0.3 & 0.5 & - & 0.03 & 0.2 & 3.9 & 0.6 & 65.2 & 1.9 & 0.7 \\
\hline $\mathbf{3}$ & 32.5 & 0.7 & 0.7 & - & 0.04 & 0.2 & 2.2 & 0.6 & 62 & 0.6 & 0.1 \\
\hline $\mathbf{4}$ & 20.3 & 0.03 & 0.4 & - & 0.03 & 0.1 & 10.5 & 1.4 & 56.8 & 8.1 & 2.1 \\
\hline
\end{tabular}

Izgled produkata korozije izloženih dejstvu rastvora kiseline koji su ispitivani EDS analizom prikazan je na slici 3, dok je hemijski sastav produkata dat u tabeli 3. Na površini dolazi do stvaranja sitnih zrnaca nastalih prilikom rastvaranja osnove sa rastvorom kiselina. U zrncima je prisutan natrijum (spec. 1 i 3), dok na neoštećenoj površini, osnovi, nema prisustva natrijuma (spec. 2).

Osim taloga natrijuma, nisu uočena druga koroziona oštećenja.

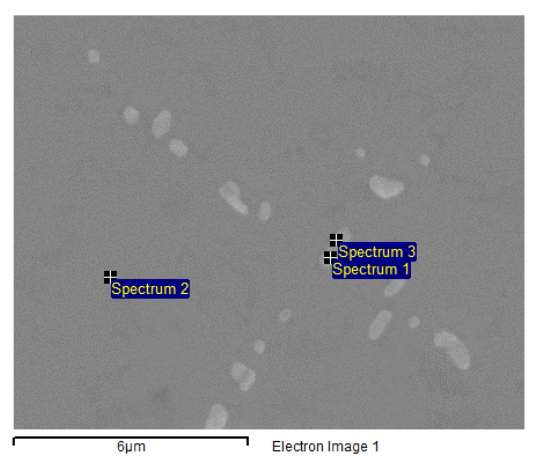

Slika 3. Mesto EDS analize na leguri nerđajućeg čelika izloženog rastvoru kiseline

Tabela 3. Hemijski sastav produkata sa slike 3 [mass. \%]

\begin{tabular}{|c|c|c|c|c|c|c|c|c|c|}
\hline Spec. & $\mathbf{C}$ & $\mathbf{N a}$ & $\mathbf{A l}$ & $\mathbf{S i}$ & $\mathbf{C r}$ & $\mathbf{M n}$ & $\mathbf{F e}$ & $\mathbf{N i}$ & $\mathbf{M o}$ \\
\hline $\mathbf{1}$ & 1.9 & 0.6 & 0.2 & 0.4 & 16.7 & 2.2 & 60.1 & 14.4 & 3 \\
\hline $\mathbf{2}$ & 2.6 & - & 0.1 & 0.4 & 16.3 & 1.9 & 62.2 & 13.6 & 2.5 \\
\hline $\mathbf{3}$ & 2.3 & 0.4 & 0.1 & 0.4 & 16.6 & 2 & 60.7 & 14.4 & 2.7 \\
\hline
\end{tabular}

\subsection{Legura titanijuma Ti-6Al-4V}

Mikrostruktura Ti-6Al-4V legure se sastoji od krupne $\beta$ faze (tamna) ravnomerno raspoređene u osnovi - $\alpha$ faze (svetla osnova). Veličina $\beta$ faze iznosi oko $10 \mu \mathrm{m}$.

Takođe, prisutna je i mala količina nemetalnih uključaka, koji su slični klasi D (oksidno globularni), veličine 1, fini, prema ASTM standardu.
Produkti korozije usled dejstva rastvora soli, ispitivani EDS analizom, prikazani su na slici 4, dok je hemijski sastav produkata dat u tabeli 4 . Nakon izlaganja uzoraka $u$ rastvoru soli došlo je do korozije na mestu železnih uključaka (nečistoća), pri čemu nastaju železni oksidi (spec. 2 do 5).

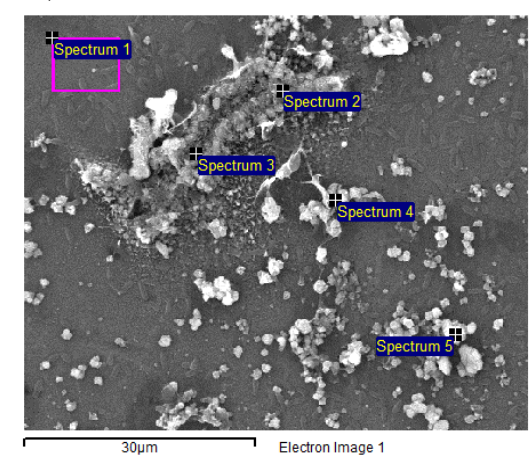

Slika 4. Mesto EDS analize na leguri titanijuma izloženog rastvoru soli

Tabela 4. Hemijski sastav produkata sa slike 4 [mass. \%]

\begin{tabular}{|c|c|c|c|c|c|c|c|c|c|}
\hline Spec. & $\mathbf{O}$ & $\mathbf{N a}$ & $\mathbf{A l}$ & $\mathbf{S i}$ & $\mathbf{C l}$ & $\mathbf{C a}$ & $\mathbf{T i}$ & $\mathbf{V}$ & $\mathbf{F e}$ \\
\hline $\mathbf{1}$ & - & - & 5.4 & - & - & - & 88.6 & 4.7 & 1.2 \\
\hline $\mathbf{2}$ & 45.5 & 0.2 & 0.7 & 0.6 & 0.15 & 0.2 & 19.8 & 0.7 & 31.9 \\
\hline $\mathbf{3}$ & 46.6 & 0.49 & 0.6 & 0.7 & 0.15 & 0.2 & 17.2 & 0.6 & 33.4 \\
\hline $\mathbf{4}$ & 36.2 & 0.5 & 2.1 & 0.3 & 0.03 & 0.1 & 46.9 & 1.3 & 12.2 \\
\hline $\mathbf{5}$ & 14.4 & 0.08 & 3.6 & 0.1 & 0.00 & 1.1 & 73.9 & 3.3 & 3.4 \\
\hline
\end{tabular}

Prilikom potapanja legure titanijuma u rastvoru kiselina dolazi do delomičnog nagrizanja površine i uočavanja $\beta$ faze u $\alpha$-osnovi, slika 5. Oštećenje površine kiselinom je ravnomerno bez nastanka posebnih produkata korozije na površini. EDS hemijski sastav površine nije detektovao značajnu razliku u hemijskom sastavu, tabela 5 .

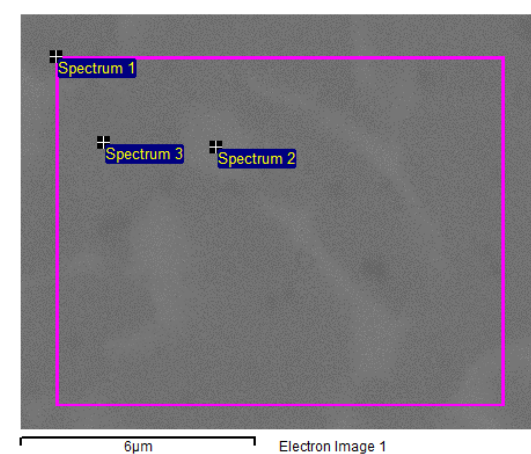

Slika 5. Mesto EDS analize na leguri titanijuma izloženog rastvoru kiseline

Tabela 5. Hemijski sastav produkata sa slike 5 [mass. \%]

\begin{tabular}{|c|c|c|c|c|}
\hline Spec. & Al & Ti & $\mathbf{V}$ & Fe \\
\hline $\mathbf{1}$ & 5.01 & 89.60 & 5.08 & 0.31 \\
\hline $\mathbf{2}$ & 4.57 & 89.51 & 5.67 & 0.25 \\
\hline $\mathbf{3}$ & 4.67 & 88.31 & 6.75 & 0.27 \\
\hline
\end{tabular}

\subsection{Legura kobalta Co-Cr-Mo}

Mikrostruktura se sastoji od svetle osnove u kojoj se nalaze $\sigma$ faza (tamna polja) i karbidi (svetla polja). U mikrostrukturi je prisutna $\mathrm{i}$ velika količina pora, nastalih verovatno prilikom skupljanja tokom livenja u međudendritskom području. Veliko prisustvo poroznosti može uticati na smanjenje mehaničkih osobina, posebno otpornosti na zamorni lom.

Izgled produkata korozije izloženih dejstvu rastvora soli koji su ispitivani EDS analizom prikazan je na slici 6 , a hemijski sastav produkata dat je u tabeli 6 . Pored konta- 
minacije površine železnim oksidom u vidu mreže, prisutne su i mešovite čestice železnog oksida (spec. 2) i taloga soli (spec. 2-4). Nije uočeno dubinsko oštećenje površine, već su produkti prisutni na površini, slika 6 .

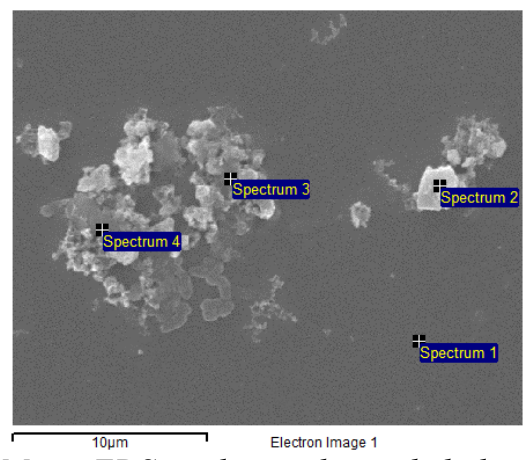

Slika 6. Mesto EDS analize na leguri kobalta izloženog rastvoru soli

Tabela 6. Hemijski sastav produkata sa slike 6 [mass. \%] \begin{tabular}{|l|l|l|l|l|l|l|l|l|l|l|l|}
\hline Spec. & O & Na & Mg & Si & Cl & Ca & Cr & Mn & Fe & Co & Mo \\
\hline
\end{tabular}

\begin{tabular}{|c|c|c|c|c|c|c|c|c|c|c|c|}
\hline $\mathbf{1}$ & - & - & - & 0.9 & - & - & 27 & 0.7 & - & 65.5 & 5.8 \\
\hline $\mathbf{2}$ & 15.9 & 0.7 & 0.3 & 1.2 & 0.3 & 0.3 & 18 & 0.5 & 17.6 & 40.2 & 4.6 \\
\hline $\mathbf{3}$ & 7.1 & 0.5 & 1.1 & 1.8 & - & 0.1 & 23.3 & 0.5 & 2.8 & 57.9 & 4.4 \\
\hline $\mathbf{4}$ & 4 & - & - & 1.2 & - & - & 25 & 0.5 & 2.2 & 62.7 & 4.2 \\
\hline
\end{tabular}

Izgled površine legure kobalta Co-Cr-Mo nakon dejstva rastvora kiseline prikazan je na slici 7 , dok je hemijski sastav uočenih mikrokonstituenata dat u tabeli 7. U mikrostrukturi osnove (spec. 1), prisutna je dendritska $\sigma$ faza (spec. 2) bogata sa hromom i molibdenom, kao i mali uključak titanijuma (spec. 3). Dejstvo kiseline utiče ravnomerno na celu površinu, pri čemu je $\sigma$ faza osetljivija i počinje da se nagriza.

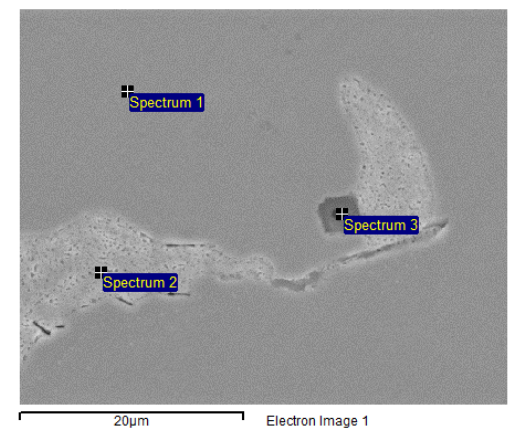

Slika 7. Mesto EDS analize na leguri kobalta izloženog rastvoru kiseline

Tabela 7. Hemijski sastav produkata sa slike 7 [mass. \%]

\begin{tabular}{|c|c|c|c|c|c|c|c|}
\hline Sp. & $\mathbf{A l}$ & $\mathbf{S i}$ & $\mathbf{T i}$ & $\mathbf{C r}$ & $\mathbf{M n}$ & $\mathbf{C o}$ & Mo \\
\hline $\mathbf{1}$ & - & 0.8 & - & 27.9 & 0.78 & 64.9 & 5.6 \\
\hline $\mathbf{2}$ & - & 0.9 & 0.2 & 38.7 & 1.06 & 43.5 & 15.6 \\
\hline $\mathbf{3}$ & 1.07 & 0.4 & 40.4 & 15.6 & 0.48 & 34.5 & 7.4 \\
\hline
\end{tabular}

\section{ZAKLJUČAK}

$\mathrm{Na}$ osnovu rezultata ispitivanja ustanovljeno je da su svi materijali otporni u većoj meri na koroziju u rastvoru soli ili kiselina. Legura Ti-6Al-4V ima najveću otpornost $\mathrm{u}$ rastvoru kiselina, dok se kod čelika 316LVM stvara sitni talog, a kod legure Co-Cr-Mo dolazi do nagrizanja mikrostrukture $(\sigma$ faza). $S$ druge strane, prilikom potapanja $u$ slani rastvor, došlo je do onečišćenja rastvora železnim česticama, i potom njihovog taloženja i korzije na površini uzoraka. U ovom slučaju potrebno je obratiti posebnu pažnju na čistoću površine materijala prilikom ugradnje u ljudsko telo, ne samo sa aspekta mikrobiološke čistoće, već i sa stajališta nežive materije (nalepljene nečistoće).

\section{LITERATURA}

[1] J. Black, G. Hastings, "Handbook of Biomaterial Properties", London UK: Chapman and Hall, 1998.

[2] B.D. Ratner, A. S. Hoffman, F. J. Schoen, J. E. Lemons, "Biomaterials Science An Introduction to Materials in Medicine”, Academic Press, San Diego, 1996.

[3] J.B. Park, R.S. Lakes, "Biomaterials An Introduction”, Plenum Press, New York, 1992.

[4] D. M. Brunette, P. Tengvall, M. Textor,

P.Thomsen, "Titanium in Medicine", Springer, Berlin, 2001.

[5] R.I.M. Asri, W.S.W. Harun, M. Samykano, N.A.C. Lah, S.A.C. Ghani, F. Tarlochan, M.R. Raza, "Corrosion and surface modification on biocompatible metals: A review", Materials Science and Engineering: C, Vol. 77, pp. 12611274, 2017.

[6] G. Manivasagam, D. Dhinasekaran, A. Rajamanickam, "Biomedical implants: corrosion and its prevention-a review", Recent Pat. Corros. Sci., Vol. 2, pp. 40-54, 2010. [7] O.O. Ige, L.E. Umoru, M.O. Adeoye, A.R. Adetunji, O.E. Olorunniwo, and I.I. Akomolafe, "Monitoring, Control and Prevention Practices of Biomaterials Corrosion - An Overview", Trends in Biomaterials and Artificial Organs, Vol. 23 (2), pp. 93-104, 2009.

[8] D.J. Medlin, R. Compton, "Metallography of Biomedical Orthopedic Alloys", Metallography and Microstructures, Vol 9, ASM Handbook, ASM International, pp. 961-968, 2004.

[9] https://www.materials.sandvik/en/materialscenter/material-datasheets/bar-anhollow-bar/bar/sandvik316lvm/ (pristupljeno u julu 2020.)

[10] A. Marti, "Cobalt-base alloys used in bone surgery, Injury”, 31, pp. 18-21, 2000.

[11] N. Eliaz, "Corrosion of Metallic Biomaterials: A Review”, Department of Materials Science and Engineering, Tel-Aviv University, Ramat Aviv 6997801, Israel, 2019.

[12] M. Robinson, "Encyclopedia of Materials: Science and Technology”, HAVAR ${ }^{\circledR}, \mathrm{A} \mathrm{Co}-\mathrm{Cr}$ Biocompatible Alloy for Medical Implants, 2005.

\section{Kratka biografija:}

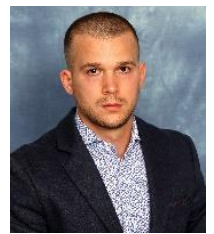

Nikola Ponjević, mast. inž. maš., rođen je u Novom Sadu 1994.g. Gimnaziju „Svetozar Marković" je završio 2013.g. u Novom Sadu, Master rad na Fakultetu tehničkih nauka iz oblasti Proizvodno mašinstvo odbranio je 2020.g.

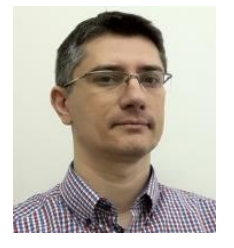

Dr Dragan Rajnović, docent, rođen je 1975.g. u Vukovaru. Diplomirao je na Fakultetu tehničkih nauka 2000.g., na kome je od tada i zaposlen u nastavi. U zvanje docenta izabran je 2015.g., za uno: Materijali i tehnologije spajanja. Specifična oblast interesovanja: mikroskopija i ispitivanje materijala. 